\title{
A case-control study of motor neurone disease: its relation to heritability, and occupational exposures, particularly to solvents
}

\author{
Lars-Gunnar Gunnarsson, Lennart Bodin, Birgitta Söderfeldt, Olav Axelson
}

\begin{abstract}
Motor neurone disease (MND) was studied in relation to various determinants in a case-control study covering nine counties in southern Sweden. A questionnaire about occupational exposures, medical history, lifestyle factors etc was given to all cases in the age range 45-79 and to a random sample of 500 population controls in the same age range. The questionnaires were answered by 92 cases and 372 controls, a response rate of $85 \%$ and $75 \%$ respectively. Among men high Mantel-Haenszel odds ratios (MHORs) were obtained for electricity work (MHOR $=6 \cdot 7,95 \%$ confidence interval $(95 \%$ CI $\quad 1 \cdot 0-32 \cdot 1)$, welding (MHOR $=3.7,95 \%$ CI 1.1-13.0), and impregnating agents (MHOR $=3.5,95 \%$ CI 0.9-13.1). Heritability with regard to a neurodegenerative disease or thyroid disease seemed to predispose to a risk of developing MND $(\mathrm{OR}=2 \cdot 1,95 \% \mathrm{CI} 1 \cdot 0-4 \cdot 3)$. The highest OR was found for the combination of such heritability, exposure to solvents, and male sex $(O R=15 \cdot 6$, $95 \%$ CI $2 \cdot 8-87 \cdot 0$ ), a combination that occurred for seven cases and three controls. Hereditary factors and external exposures had a different distribution among cases with the spinal type of MND than among cases with involvement of the pyramidal tract or bulbar paresis also.
\end{abstract}

(British Journal of Industrial Medicine 1992;49:791-8)

Motor neurone disease (MND) is a neurodegenerative disease with an inexorable progressive and fatal course. It encompasses the diagnoses of

Department of Occupational Medicine, Örebro Medical Centre, Örebro, Sweden

L G Gunnersson, L Bodin

Department of Neurology, University Hospital, Lin-

köping, Sweden

B Söderfeldt

Department of Occupational Medicine, University

Hospital, Linköping, Sweden

O Axelson amyotrophic lateral sclerosis (ALS), progressive bulbar palsy (PBP), and progressive muscular atrophy (PMA). The mean duration of the different types of MND together is between two and three years, ${ }^{1-3}$ usually less than two years for PBP, and more than five years for PMA. ${ }^{23}$ The aetiology is still unclear but the past two decades of research have given increasing support to the hypothesis that environmental factors may have an aetiological role. Most evidence in this respect emanates from the studies concerning ALS in Guam, indicating an influence from ingested neurotoxins, glutamate, and other excitatory aminoacids ${ }^{4}$ or nutritional deficiencies of calcium or magnesium. ${ }^{5}$

A heterogenetic pattern of environmental and occupational factors associated with MND has appeared in several epidemiological studies. Most of these studies, however, had a secondary study base $^{6}$ - that is, the controls had been selected from among other patients, ${ }^{17-14}$ among healthy subjects who were mostly relatives or friends, ${ }^{15-21}$ or among persons who were both. ${ }^{22-24}$ Only in two studies ${ }^{25} 26$ were the controls drawn randomly from a primary study base, as would be preferable. ${ }^{6}$ In these two studies the information on exposure was rather poor, being register based only.

The aim of the present case-control study was to obtain more reliable information on the aetiology of MND through use of a random sample from a primary study base and reasonably detailed data on exposure.

\section{Methods}

STUDY POPULATION

The study was carried out in central and southern Sweden, covering the counties of (administratively used letters in parentheses) Östergötland (E), Jönköping (F), Kalmar (H), Kristianstad (L), Malmöhus $(\mathbf{M})$, Älvsborg (P), Skaraborg (R), Värmland (S), and Örebro (T). The study population was limited to those aged 45-79 and consisted of 1.2 million inhabitants. This population was represented by 500 controls randomly selected from the national population register. 
SELECTION OF CASES

At the beginning of 1990 all departments of neurology and internal medicine in the study area received a postal inquiry inquiring whether they had any patients with MND. These departments were then visited and the medical records for the patients in whom MND was suspected were scrutinised.

Pure motor symptoms, a progressive course, and no signs of polyneuropathia were required for the diagnosis of MND. To be accorded the diagnosis ALS the cases were required to have lower motor neurone symptoms in at least two regions (arms, legs, bulbar) together with evident symptoms of upper motor neurone involvement within three years after onset. Cases with a bulbar paresis as dominating symptom but without evident symptoms of affected upper motor neurones were designated PBP. The other cases with only lower motor neurone involvement during the first three years after onset were designated PMA. For some of those cases there was not enough information available in the medical records and the diagnosis could only be taken as probable. A total of 112 patients diagnosed with MND in the age range 45-79 were identified in the study area.

\section{ASSESSMENT OF INDIVIDUAL FACTORS AND} OCCUPATIONAL EXPOSURES

Information on earlier and current occupation and residence was gathered by means of a self administered questionnaire, which also included questions about exposure to different physical and chemical factors. The questionnaire also inquired about handling animals, physical exercise, use of tobacco or alcohol, medical history, medication, dental amalgam fillings, and heritability. The subjects were asked about their eating habits during the 1960 s, 1970s, and 1980 s such as use of aluminium cooking utensils, frequent use of locally cultivated foodstuffs, freshwater fish, cheese, milk, tinned food, and food from restaurants. The rationale for these questions was the suspicion that chemical agents used in the neighbourhood and dietary exposure to glutamate possibly had an aetiological role. In total, the questionnaire encompassed 46 main questions, some of which had several further specifications.

During the spring of 1990 , the questionnaires were mailed to all cases and controls. Eight questionnaires (four cases and four controls) were returned because of wrong addresses. When these subjects were checked with the population register, apparently one of the controls had just died but the other seven were alive. Altogether 496 controls and 108 cases were identified and received the questionnaire. To compare respondents and non-respondents information for all controls was obtained from the census of 1980 . They were compared with respect to age, residence, and occupational affiliation.
The mean duration of MND for the cases was five years. Exposures among the controls occurring less than five years before 1990 were excluded to obtain comparability between cases and controls with respect to relevant exposure. For the cases, only exposures that had occurred in the last year before the onset of MND at the latest were registered.

\section{STATISTICAL METHODS}

Crude odds ratios (ORs) and adjusted Mantel-Haenszel odds ratios (MHORs) along with the exact $95 \%$ confidence intervals ( $95 \%$ CIs) were calculated using the EPIINFO statistical package. ${ }^{27}$ The influence of different factors on the estimated risk of being afflicted with MND was analysed by bimodal and multinomial logistic regressions using the EPILOG and SYSTAT statistical packages and 95\% CIs (large sample formulas) were calculated for the ORs. ${ }^{2829}$ The analyses were performed in several steps.

As a first step, a number of tentative risk factors were identified. They were assumed to be associated with MND and selected on the basis of both the calculated crude ORs and the condition that at least 10 subjects were exposed. The subsequent analyses of different combinations of these factors were carried out on the subset of subjects that had data on all of the selected variables. Based on these factors, a model was constructed with an acceptable fit. As no evident dose-response relation appeared, the included variables of exposure were dichotomised. Also the age variable was dichotomised at 61 years-that is, the shift in the cumulative age distribution of ALS or PBP (see figure 2). The variables were entered into the model additively. Thus no terms of interaction were introduced at this stage.

In a second step, further variables of exposure were introduced. The criteria for inclusion were an improved model fit and evidently diverging risk estimates.

In a third step, terms of interaction between the previously selected variables of exposure were introduced-that is, different combinations of exposures and factors were tested. When a term of interaction caused an improved model fit it was accepted, and the model was recategorised. Simplicity in the model structure was striven for.

At first the models were tested with all cases against the controls. Then the cases were separated into those with ALS or PBP, those with a certain diagnosis of PMA, and those with only a probable diagnosis of PMA, to analyse possible differences between these three classifications. This analysis was performed in two different ways; either by means of separate (binary) logistic regressions with one of these categories against the controls, or by means of a multinomial logistic model with four possible outcomes, cases with ALS or PBP, cases with probable PMA, cases with certain PMA, and controls. The 
advantage of the multinomial model is the possibility of exactly reproducing the proportions in the four categories. With separate regressions this is not always possible. On the other hand separate regressions give the opportunity for different modelling of the selected categories of cases.

\section{Results}

Completed questionnaires were received from 92 cases of MND (58 men and 34 women) and 372 controls ( 189 men and 183 women), corresponding to a response rate of $85 \%$ among the cases (men $83 \%$ and women $89 \%$ ) and $75 \%$ among the controls (men $74 \%$ and woman $75 \%$ ). Among the controls the proportion of respondents was proportionately low among those working in agriculture or forestry $(63 \%)$ but among the cases, this proportion was equal to other occupations. The response rate between the different counties ranged from 61 to $83 \%$ for the controls and from 74 to $100 \%$ for the cases (fig 1 ).

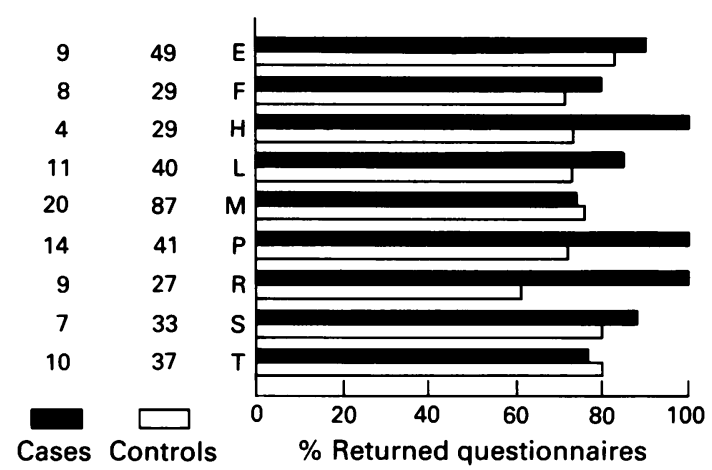

Figure 1 Number and percentage of cases and controls who answered the questionnaires and their distribution over the nine Swedish counties ( $E-T)$.

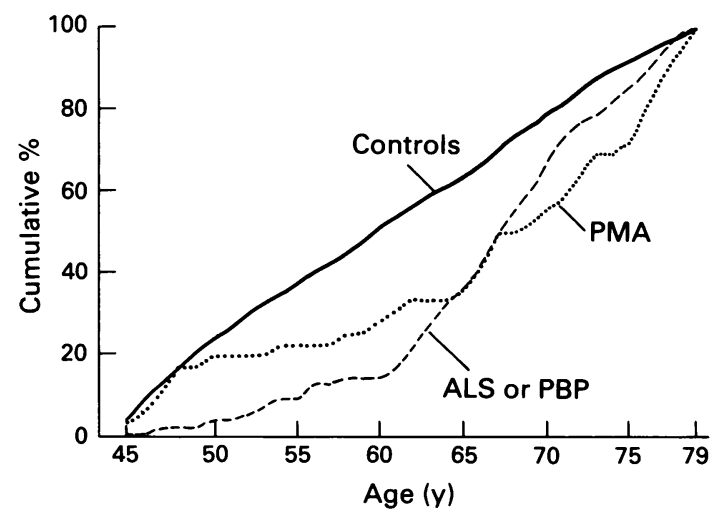

Figure 2 Cumulative age distribution of the 372 controls, the 36 cases afflicted with progressive muscular atrophy (PMA), and the 56 cases afflicted with $A L S$ or PBP.
The age distribution was different for the various subgroups of MND (fig 2). For ALS or PBP there was a pronounced increase after the age of 61 but for PMA most cases were younger than 50 or older than 64.

\section{INTERNAL FACTORS}

Age was the most prominent risk factor for $\mathrm{MND}$, giving $\mathrm{OR}=6.8$ for $\mathrm{ALS}$ or $\mathrm{PBP}$ and $\mathrm{OR}=2.7$ for PMA when those over 61 were compared with younger subjects (table 1 ).

Heritability for Alzheimer's disease, Parkinson's disease, ALS, and thyroid disease was associated with a raised risk of MND ( $M H O R=2 \cdot 1$; table 2 ), and no difference was found between ALS or PBP and PMA.

\section{EXTERNAL FACTORS}

Table 3 shows the risk estimates for occupational exposures among men. Only three women reported occupational exposure to physical factors and six to chemical agents, and the risk estimates were in the same range as for the men. For the non-occupational exposures the risk estimates were similar for both sexes, and thus men and women were treated together (table 2). Because of the limited number of cases, the confidence limits were wide for most risk estimates. The risk estimates were low for most occupational exposures but high MHORs were found for exposure to electricity work (6.7), welding (3.7), and impregnating agents (3.5). Exposure to any solvent seemed to increase the risk of MND mainly in the youngest age group (table 3 ) and among cases with PMA (table 4).

Among the chemical agents a comparatively common exposure was reported only for solvents, and 27 men and three women reported a mean exposure time of 10 and three years respectively. For the controls the corresponding figures were 88 men ( 10 years) and 28 women (five years). For both cases and controls most solvent exposures were to aromatic hydrocarbons, mixed volatile hydrocarbons, and petrol. Exposure to aromatic hydrocarbons was more common among the cases, whereas exposure to halogenated hydrocarbons was more common among the controls.

Exposure to heavy metals, mainly through welding, gave raised ORs for all age groups (table 3 ). Among the men eight cases and eight controls had been exposed to welding. The cases had been exposed for a mean of 17 years and the controls for 18 years.

Preceding trauma did not seem to be a risk factor for MND (tables 4 and 5).

In the final model age and exposure to heavy metals, mainly in welding, came out as independent risk factors with significantly raised risk estimates (table 1). The combination of male sex, exposure to 
solvents, and heritability of neurodegenerative disease or thyroid disease involved the highest ORs (table 1) and was found for seven cases and three controls. Four had ALS or PBP, two had certain PMA, and one had probable PMA. The risk estimates for this combination were large for the subgroups of MND irrespective of whether they were analysed separately by means of bimodal logistic regression or together by means of multinomial regression (table 1). Successive adding of other possible risk factors to the model, such as contact with animals, physical trauma (fracture or surgery),

Table 1 Risk estimates derived from regression analyses in the final model

\begin{tabular}{|c|c|c|c|}
\hline & $\begin{array}{l}\text { Age } 61+ \\
O R(95 \% C I)\end{array}$ & $\begin{array}{l}\text { Heavy metals } \\
\text { OR }(95 \% C I)\end{array}$ & $\begin{array}{l}\text { Men }+ \text { Solvents } \\
+ \text { Heritability } \\
O R(95 \% C I)\end{array}$ \\
\hline \multicolumn{4}{|c|}{ Separate logistic regression } \\
\hline $\begin{array}{l}\text { PMA/ALS/PBP 90/362 } \\
\text { ALS/PBP 55/362 } \\
\text { PMA (certain) 29/362 } \\
\text { PMA (probable) 6/362 } \\
\text { PMA (all) } 35 / 362\end{array}$ & $\begin{array}{l}4 \cdot 4(2 \cdot 5-7 \cdot 9) \\
7 \cdot 4(3 \cdot 2-16 \cdot 9) \\
2 \cdot 8(1 \cdot 2-6 \cdot 4) \\
1 \cdot 8(0 \cdot 3-10 \cdot 7) \\
2 \cdot 6(1 \cdot 2-5 \cdot 6)\end{array}$ & $\begin{array}{c}1 \cdot 9(0 \cdot 8-4 \cdot 4) \\
1 \cdot 0(0 \cdot 3-3 \cdot 3) \\
2 \cdot 1(0 \cdot 6-7 \cdot 2) \\
12 \cdot 9(2 \cdot 3-73 \cdot 4) \\
3 \cdot 2(1 \cdot 2-8 \cdot 7)\end{array}$ & $\begin{array}{l}15 \cdot 6(2 \cdot 8-87 \cdot 0) \\
25 \cdot 1(3 \cdot 6-175 \cdot 8) \\
10 \cdot 0(1 \cdot 2-81 \cdot 6) \\
19 \cdot 6(0 \cdot 9-447 \cdot 2) \\
10 \cdot 4(1 \cdot 5-74 \cdot 3)\end{array}$ \\
\hline \multicolumn{4}{|c|}{ Multinomial logistic regression } \\
\hline $\begin{array}{l}\text { ALS/PBP 55/362 } \\
\text { PMA (certain) }{ }^{\star} 29 / 362 \\
\text { PMA (probable) }{ }^{\star} 6 / 362 \\
\text { PMA (all) }{ }^{\star} 35 / 362\end{array}$ & $\begin{array}{l}6 \cdot 8(3 \cdot 1-15 \cdot 1) \\
2 \cdot 9(1 \cdot 2-6 \cdot 8) \\
1 \cdot 8(0 \cdot 3-10 \cdot 8) \\
2 \cdot 7(1 \cdot 2-5 \cdot 9)\end{array}$ & $\begin{array}{c}0 \cdot 9(0 \cdot 3-3 \cdot 0) \\
2 \cdot 1(0 \cdot 6-6 \cdot 8) \\
12 \cdot 5(2 \cdot 2-70 \cdot 1) \\
3 \cdot 2(1 \cdot 2-8 \cdot 6)\end{array}$ & $\begin{array}{l}18 \cdot 2(2 \cdot 8-118 \cdot 4) \\
13 \cdot 0(1 \cdot 6-105 \cdot 4) \\
20 \cdot 3(1 \cdot 2-335 \cdot 4) \\
14 \cdot 2(2 \cdot 0-100 \cdot 1)\end{array}$ \\
\hline
\end{tabular}

*Two multinomial regressions were performed, one with PMA separated into certain and probable cases and one with all cases of PMA. Because of missing information about heredity, two cases and 10 controls were excluded from these analyses and the numbers included are indicated as cases/controls.

Table 2 Crude ORs by age for men and women together and Mantel-Haenszel ORs (MHORs) stratified on age and sex for some exposures and internal factors

\begin{tabular}{|c|c|c|c|c|c|}
\hline & \multicolumn{4}{|l|}{ Age } & \multirow[b]{2}{*}{ No $(95 \% C I)$} \\
\hline & $\begin{array}{l}45-59 \\
O R\end{array}$ & $\begin{array}{l}60-69 \\
O R\end{array}$ & $\begin{array}{l}70-79 \\
O R\end{array}$ & $\begin{array}{l}45-79 \\
M H O R\end{array}$ & \\
\hline $\begin{array}{l}\text { Physical factors: } \\
\text { Athletics } \\
\text { Physical exercise } \\
\text { Difficulty in relaxing } \\
\text { Muscular tensions }\end{array}$ & $\begin{array}{l}2 \cdot 3 \\
0.6 \\
0.5 \\
0.5\end{array}$ & $\begin{array}{l}1.0 \\
0.5 \\
1.0 \\
1.4\end{array}$ & $\begin{array}{l}- \\
1 \cdot 1 \\
1.5 \\
1 \cdot 4\end{array}$ & $\begin{array}{l}0 \cdot 7 \\
0 \cdot 7 \\
0 \cdot 9 \\
1 \cdot 2\end{array}$ & $\begin{array}{l}12(0 \cdot 3-1 \cdot 6) \\
36(0 \cdot 4-1 \cdot 1) \\
13(0 \cdot 4-1 \cdot 9) \\
37(0 \cdot 7-2 \cdot 0)\end{array}$ \\
\hline $\begin{array}{l}\text { Biological agents: } \\
\text { Handling dogs in free time }\end{array}$ & 0.9 & 0.5 & 0.4 & 0.5 & $31(0 \cdot 3-0 \cdot 9)$ \\
\hline $\begin{array}{l}\text { Habits during more than two decades: } \\
\text { Cooking with aluminium utensils } \\
\text { Locally cultivated foodstuffs } \\
\text { Freshwater fish every week } \\
\text { Three or more slices of cheese each day } \\
6 \text { dl or more of milk each day } \\
\text { Restaurant food } \geqslant 4 \text { days a week }\end{array}$ & $\begin{array}{l}2 \cdot 6 \\
1 \cdot 1 \\
0.9 \\
0 \cdot 7 \\
1 \cdot 4 \\
1 \cdot 3\end{array}$ & $\begin{array}{l}1.0 \\
0.6 \\
0.7 \\
1.4 \\
1.1 \\
0.8\end{array}$ & $\begin{array}{l}0 \cdot 7 \\
0 \cdot 7 \\
0 \cdot 1 \\
0 \cdot 3 \\
0 \cdot 9 \\
0 \cdot 6\end{array}$ & $\begin{array}{l}1 \cdot 1 \\
0 \cdot 7 \\
0 \cdot 4 \\
0 \cdot 6 \\
1 \cdot 0 \\
0 \cdot 8\end{array}$ & $\begin{array}{r}20(0 \cdot 5-2 \cdot 5) \\
14(0 \cdot 4-1 \cdot 5) \\
7(0 \cdot 2-1 \cdot 0) \\
47(0 \cdot 3-1 \cdot 1) \\
45(0 \cdot 6-1 \cdot 7) \\
10(0 \cdot 3-1 \cdot 7)\end{array}$ \\
\hline $\begin{array}{l}\text { Diseases: } \\
\text { Thyroid disease } \\
\text { Pernicious anaemia } \\
\text { Gastric ulcer } \\
\text { Fracture in past } 10 \text { years } \\
\text { Fracture 11- } 35 \text { years before onset of MND } \\
\text { Surgery in past } 10 \text { years } \\
\text { Surgery } 11-35 \text { years before onset of MND }\end{array}$ & $\begin{array}{l}- \\
- \\
2 \cdot 0 \\
1.7 \\
1.6 \\
2.9 \\
0.6\end{array}$ & $\begin{array}{l}2.0 \\
3.0 \\
1.6 \\
1.3 \\
1.3 \\
1.0 \\
1.0\end{array}$ & $\begin{array}{l}2 \cdot 3 \\
+ \\
2 \cdot 3 \\
1 \cdot 2 \\
0 \cdot 6 \\
0 \cdot 4 \\
0 \cdot 7\end{array}$ & $\begin{array}{l}1.5 \\
3 \cdot 6 \\
1.9 \\
1.6 \\
0.9 \\
0.9 \\
0 \cdot 8\end{array}$ & $\begin{array}{l}3(0 \cdot 2-6 \cdot 1) \\
2(0 \cdot 2-30 \cdot 8) \\
5(0 \cdot 5-6 \cdot 4) \\
14(0 \cdot 7-3 \cdot 2) \\
13(0 \cdot 4-1 \cdot 9) \\
23(0 \cdot 5-1 \cdot 6) \\
26(0 \cdot 5-1 \cdot 4)\end{array}$ \\
\hline $\begin{array}{l}\text { Heritability: } \\
\text { Parkinson's disease } \\
\text { Alzheimer's disease } \\
\text { MND } \\
\text { Thyroid disease } \\
\text { Diabetes } \\
\text { APAT }\end{array}$ & $\begin{array}{l}1 \cdot 9 \\
3 \cdot 3 \\
+ \\
2 \cdot 4 \\
1 \cdot 4 \\
2 \cdot 4\end{array}$ & $\begin{array}{l}6.1 \\
0.8 \\
+ \\
2 \cdot 4 \\
1.7 \\
1.9\end{array}$ & $\begin{array}{l}2.4 \\
- \\
1 \cdot 2 \\
2.4 \\
0.7 \\
1.5\end{array}$ & $\begin{array}{l}2 \cdot 5 \\
1 \cdot 2 \\
4 \cdot 0 \\
2 \cdot 7 \\
1 \cdot 2 \\
2 \cdot 1\end{array}$ & $\begin{array}{c}5(0 \cdot 5-10 \cdot 2) \\
3(0 \cdot 2-5 \cdot 0) \\
3(0 \cdot 5-62 \cdot 0) \\
7(0 \cdot 8-7 \cdot 7) \\
18(0 \cdot 6-2 \cdot 3) \\
15(1 \cdot 0-4 \cdot 3)\end{array}$ \\
\hline
\end{tabular}

$+=$ Exposed controls are missing; $-=$ exposed cases are missing; No $=$ number of exposed cases. APAT = Alzheimer's disease, Parkinson's disease, amyotrophic lateral sclerosis, and/or thyroid disease. 
Table 3 Crude ORs by age for men and Mantel-Haenszel ORs (MHORs) stratified on age for different occupational exposures

\begin{tabular}{|c|c|c|c|c|c|}
\hline & \multicolumn{4}{|l|}{ Age } & \multirow[b]{2}{*}{ No $(95 \% C I)$} \\
\hline & $\begin{array}{l}45-59 \\
O R\end{array}$ & $\stackrel{60-69}{O R}$ & $\begin{array}{l}70-79 \\
O R\end{array}$ & $\begin{array}{l}45-79 \\
M H O R\end{array}$ & \\
\hline $\begin{array}{l}\text { Physical factors: } \\
\text { Electricity work } \\
\text { Electromagnetic fields } \\
\text { Shocks from low current } \\
\text { Shocks from heavy current } \\
\text { Vibrations }\end{array}$ & $\begin{array}{l}3 \cdot 6 \\
- \\
4 \cdot 1 \\
0.6 \\
0.9\end{array}$ & $\begin{array}{l}+ \\
2 \cdot 1 \\
1 \cdot 0 \\
0 \cdot 8 \\
1 \cdot 1\end{array}$ & $\begin{array}{l}- \\
0 \cdot 7 \\
0.9 \\
0 \cdot 8\end{array}$ & $\begin{array}{l}6 \cdot 7 \\
0 \cdot 6 \\
1 \cdot 2 \\
0 \cdot 8 \\
1 \cdot 0\end{array}$ & $\begin{array}{c}4(1 \cdot 0-32 \cdot 1) \\
4(0 \cdot 2-2 \cdot 0) \\
12(0 \cdot 5-2 \cdot 8) \\
4(0 \cdot 2-2 \cdot 7) \\
28(0 \cdot 5-1 \cdot 9)\end{array}$ \\
\hline $\begin{array}{l}\text { Chemical agents: } \\
\text { Alcohol } \\
\text { Aromatic hydrocarbons } \\
\text { Mixed volatile hydrocarbons } \\
\text { Halogenated hydrocarbons } \\
\text { Petrol } \\
\text { Any solvent } \\
\text { Pesticides and insecticides } \\
\text { Impregnating agents } \\
\text { Aluminium } \\
\text { Lead } \\
\text { Mercury } \\
\text { Manganese } \\
\text { Welding } \\
\text { Any heavy metal (iron included) } \\
\text { Any chemical agent }\end{array}$ & $\begin{array}{l}- \\
1.8 \\
0.5 \\
1.7 \\
2.5 \\
3 \cdot 2 \\
2.8 \\
4.2 \\
0.9 \\
- \\
- \\
6.2 \\
1.7 \\
2.4\end{array}$ & $\begin{array}{l}2.7 \\
0.9 \\
0.9 \\
0.8 \\
1.3 \\
1.1 \\
+ \\
1.3 \\
1.3 \\
3.9\end{array}$ & $\begin{array}{l}1 \cdot 3 \\
3 \cdot 2 \\
0.9 \\
- \\
1 \cdot 0 \\
0 \cdot 9 \\
- \\
6 \cdot 1 \\
- \\
+ \\
- \\
- \\
3 \cdot 9 \\
1 \cdot 1 \\
0.7\end{array}$ & $\begin{array}{l}1 \cdot 3 \\
1 \cdot 7 \\
0 \cdot 8 \\
0 \cdot 7 \\
1 \cdot 4 \\
1 \cdot 3 \\
1 \cdot 1 \\
3 \cdot 5 \\
0 \cdot 9 \\
2 \cdot 8 \\
0 \cdot 4 \\
3 \cdot 7 \\
1 \cdot 6 \\
1 \cdot 1\end{array}$ & $\begin{array}{l}3(0 \cdot 2-6 \cdot 6) \\
14(0 \cdot 8-3 \cdot 8) \\
11(0 \cdot 4-1 \cdot 8) \\
4(0 \cdot 2-2 \cdot 5) \\
15(0 \cdot 7-3 \cdot 0) \\
30(0 \cdot 7-2 \cdot 5) \\
3(0 \cdot 2-5 \cdot 3) \\
5(0 \cdot 9-13 \cdot 1) \\
3(0 \cdot 2-3 \cdot 9) \\
6(0 \cdot 7-9 \cdot 2) \\
0 \\
1(0 \cdot 01-3 \cdot 2) \\
8(1 \cdot 1-13 \cdot 0) \\
10(0 \cdot 7-3 \cdot 9) \\
34(0 \cdot 6-2 \cdot 2)\end{array}$ \\
\hline $\begin{array}{l}\text { Biological agents: } \\
\text { Handling of any animal at work }\end{array}$ & 3.5 & $2 \cdot 0$ & 0.3 & 1.2 & $13(0 \cdot 5-2 \cdot 6)$ \\
\hline
\end{tabular}

+ Exposed controls are missing; - exposed cases are missing; No = number of exposed cases.

Table 4 Relations (men and women together) between exposure to solvents and trauma (fracture or surgery) less than 10 years before onset of PMA

\begin{tabular}{lcclcc}
\hline & \multicolumn{2}{c}{ Trauma absent } & & \multicolumn{2}{l}{ Preceding trauma } \\
\cline { 2 - 3 } \cline { 5 - 6 } & \multicolumn{2}{l}{ Solvents } & & \multicolumn{2}{l}{ Solvents } \\
& - & + & & - & + \\
\hline No of cases & 12 & 11 & & 7 & 6 \\
No of controls & 178 & 65 & & 79 & 50 \\
OR & 1.0 & 2.5 & & 1.3 & 1.8 \\
$95 \%$ CI & & $1.0-6.5$ & & $0.4-3.8$ & $0.5-5.4$ \\
\hline
\end{tabular}

Table 5 Relations (men and women together) between exposure to solvents and trauma (fracture or surgery) less than 10 years before onset of $A L S$ or PBP

\begin{tabular}{|c|c|c|c|c|}
\hline & \multicolumn{2}{|c|}{ Trauma absent } & \multicolumn{2}{|c|}{ Preceding trauma } \\
\hline & $\begin{array}{l}\text { Solven } \\
-\end{array}$ & ${ }^{t s}+$ & Solvents & + \\
\hline $\begin{array}{l}\text { No of cases } \\
\text { No of controls } \\
\text { OR } \\
95 \% \text { CI }\end{array}$ & $\begin{array}{c}24 \\
178 \\
1.0\end{array}$ & $\begin{array}{l}12 \\
65 \\
1.4 \\
0 \cdot 6-3 \cdot 0\end{array}$ & $\begin{array}{l}15 \\
79 \\
1 \cdot 4 \\
0 \cdot 7-3 \cdot 0\end{array}$ & $\begin{array}{l}5 \\
50 \\
0 \cdot 7 \\
0 \cdot 2-2 \cdot 1\end{array}$ \\
\hline
\end{tabular}

use of aluminium cooking utensils, and lack of exercise, did not create any better fit.

The mean number of dental amalgam fillings was 10 for the cases and 12 for the controls with only slight variation by sex and age.

\section{Discussion}

Hereditary factors seem to play a part in the development of MND. Also the results indicated that exposure to chemical agents may increase the risk of developing $M N D$, especially among men younger than 60 . Using statistical modelling, one combination gave a high risk estimate, namely that of male sex, exposure to solvents, and heritability for neurodegenerative disease or thyroid disease.

Many methodological problems are inherent in an epidemiological study of this kind, particularly issues of internal validity. In our study, the controls were randomly selected and therefore likely to be representative of the study population. We also tried to identify and include all cases who were alive at the time of our visit to the hospitals in question. The response rate $(\mathbf{7 5} \%)$ among controls was rather low. According to the census of 1980,30 of the controls worked in agriculture or forestry, but only 19 of these $(63 \%)$ returned the questionnaires. Such work may have relatively high chemical exposure especially to pesticides and insecticides and perhaps also to solvents and welding. Thus chemical exposure among the controls could be underestimated, implying that risk estimates for chemical exposure are too high. The risk estimates obtained would not be explained by this slight bias, however, only moderately changed.

Several factors given in table 3 show the highest ORs among the youngest subjects. This might 
depend on the low background rate in lower ages permitting any particular risk factor to appear more clearly than in higher ages with a high background. It could perhaps also be that the younger cases had a tendency towards better recall of exposure to occupational factors, whereas the older cases underreported such exposure because of impaired memory. Case-control studies are usually criticised because of the possibility of recall bias, implying that the cases may recall exposure better than the controls. Hence, the subjects with chronic diseases other than the one under study might also report certain exposures more often than those who are healthy in all respects. Because the controls in our study were a random sample, they contained subjects with chronic diseases other than MND and they could be ascertain whether there was any tendency to recall bias. For this purpose the disorders should be frequent enough and not known to be associated with the exposures of interest. To check for recall bias we chose diabetes and gastric ulcer, which occurred in 14 and 11 controls respectively. We found no association between these disorders and reported exposure to solvents among men, women, those under age 66 , or those over age $65(0.7<\mathrm{OR}<1 \cdot 3)$.

The assessment of diagnosis is a potential source of error. Almost all cases had been examined by a neurologist or by a doctor of internal medicine. Forty cases were designated as having ALS and 16 cases progressive bulbar palsy (PBP). Among cases with progressive muscular atrophy (PMA) the natural course of the disease is slower and the diagnosis is more difficult to establish. There was no doubt about the diagnosis for 30 (certain cases) of the 36 cases designated as having PMA, and the diagnosis was confirmed by neurophysiological examination for 26 of those. More than three years after the onset of MND two of the cases of PMA developed upper motor neurone symptoms. Probably several of the other PMA cases also developed upper motor neurone symptoms later in the course of the disease. Such symptoms were not evident, however, at the time of the neurological examination reported in the medical records scrutinised during the spring of 1990. All cases with PMA were affected in the arms and the legs. For six cases (five men) with PMA the diagnosis was judged to be only probable. These six cases were treated separately in the regression analyses (table 1). In the spring of 1990 the median duration of illness was four years. Nerve conduction velocities were examined in the case of three of the six and were certified normal.

Another methodological problem is that of confounding. Potential confounding requires an association between two determinants among the controls. ${ }^{30}$ In our study some exposures were associated with each other and thus could be confounders, as indicated by the degree of association among the controls when using ORs as a measure of this association (not to be confused with ORs as estimates of risk). The strongest association was between solvents and impregnating agents $(\mathrm{OR}=3 \cdot 2)$, solvents and insecticides or pesticides ( $O R=3 \cdot 0)$, solvents and heavy metals (mainly welding) $(\mathrm{OR}=4 \cdot 0)$, solvents and contact with animals $(\mathrm{OR}=2 \cdot 2)$, and insecticides or pesticides and contact with animals $(O R=8 \cdot 6)$. This could indicate that the different chemical agents could be confounders with regard to each other, if exerting risk. Also, occupational exposure to chemical agents could be a confounder for exposure to animals. To a large extent the occupational exposures, therefore, had to be considered in aggregate. Most ORs for exposures to chemical agents were higher than the OR for occupational exposure to animals. Thus exposure to chemical agents seemed to be a confounder with regard to exposure to animals, which itself was not a risk factor for MND.

Age was found to be the most prominent risk factor for MND. This is in accordance with all other epidemiological studies concerning MND in which the age specific incidence rates increase with age, at least up to 75, as discussed in a study of MND in Sweden during 25 years. ${ }^{31}$

In four case-control studies, heritability of neurodegenerative disease has been studied and an association with MND appeared in three of them ${ }^{16}{ }^{1924} ;$ no association was found in one. ${ }^{17}$ Also an association between MND and thyroid disease was suggested. A high density of receptors for thyrotrophin releasing hormone (TRH) exists in the anterior horn of the spinal cord and the TRH spinal system is thought to be involved in the pathophysiological alterations of ALS. ${ }^{32}$ Our study indicated an enhanced susceptibility to MND among those with heritability of neurodegenerative disease or thyroid disease.

Several case-control studies have considered MND and exposure to chemical agents. A positive association was found between MND and exposure to heavy metals in six studies ${ }^{81316172224}$ whereas no association was found in three studies. ${ }^{121921}$ Other chemical agents (mostly solvents) were shown to be associated with MND in four studies ${ }^{14171921}$ but no association was found in one. ${ }^{23}$

In our study solvents appeared to be a risk factor for MND especially among those under 60 years of age or in combination with genetic disposition. A total of 12 cases were exposed to a heavy metal. The risk estimates for exposure to heavy metals were unchanged between the three age groups but varied considerably between the subtypes of MND (table 1). Heavy metals seemed to be a risk factor for PMA, with the highest ORs for those with an only probable diagnosis. This could indicate that the degenerative process of MND in the lower motor neuron was 
triggered by heavy metals. Alternatively, it could be interpreted as indicating that one or two cases with recorded PMA in fact might have motor neuropathy caused by metal intoxication, and not PMA.

Fractures, surgery, or other physical trauma have been shown to be associated with MND in most studies $^{8-111314161719212325}$ although not in four. ${ }^{122024}$ In our study fractures less than 10 years before onset of MND were the only type of trauma that produced a raised MHOR (1.6), whereas there was no risk from surgery $(O R=0.9)$; (table 2 ).

An association, in terms of $O R$, was found between solvents and physical trauma (fracture or surgery less than 10 years before onset of $M N D)(O R=1.9)$. The risk estimates varied between the different types of MND and a combination of determinants involved the highest risk estimates (table 1). In tables 4 and 5 exposures were stratified on physical trauma and solvents and the risk estimates were analysed separately for cases with ALS or PBP and cases with PMA. Physical trauma did not seem to be a risk factor with regard to MND, either as a single determinant or in combination with solvents. Exposure to solvents might be a confounder, however, with regard to physical trauma.

Our study showed increased risk of MND among men working with electricity. In two other studies, preceding electric injury or shock was found more often among cases afflicted with MND. ${ }^{11}$ Our study did not indicate that electric shocks were a risk factor for developing MND, but strong association existed between work with electricity and exposure to heavy metals and solvents. The ORs for the association were 2.5 and 4.6 respectively. The risks in terms of ORs for these exposures were considerably lower than the ORs for electricity work, however, (1.6 and 1.3 compared with $6 \cdot 7$ ). Thus also other factors (not yet identified) associated with electrical work might exert an increase risk for MND.

The most important explanation, apart from random phenomena, of the diverging results in the quoted case-control studies might be that the controls only partly represented the distribution of tentative risk factors for MND in the population. Nevertheless several studies have indicated chemical agents as risk factors.

This study used an epidemiological design with a random sample of controls from a primary study base and confirmed the results from other studies in so far as some chemical agents appeared as risk factors for MND, especially among genetically predisposed subjects. Further studies using proper epidemiological designs are needed to confirm or refute these results and to establish which agents bring the greatest risks. Furthermore, the interactions between external and inherent factors need to be clarified.

This project was supported by grants from the
Örebro County Council Research Committee, the Örebro Medical Centre Research Foundation, and the Swedish Work Environment Fund.

Requests for reprints to: Lars-Gunnar Gunnarsson, Department of Neurology, Örebro Medical Centre Hospital, 70185 Örebro, Sweden.

1 Li T-M, Alberman E, Swash M. Clinical features and associations of 560 cases of motor neurone disease. J Neurol Neurosurg Psychiatry 1990;53:1043-5.

2 Gunnarsson L-G, Palm R. Motor neuron disease and heavy manual labor: An epidemiologic survey of Värmland county, Sweden. Neuroepidemiology 1984;3:195-206.

3 Rosen AD. Amyotrophic lateral sclerosis, clinical features and prognosis. Arch Neurol 1978;35:638-42.

4 Spencer PS. Guam ALS/parkinsonism-dementia: a long latency neurotoxic disorder caused by "slow toxin(s)" in food. Can J Neurol Sci 1987;14(suppl 3):347-57.

5 Garruto RM, Yanagihara R, Gajdusek C. Disappearance of high-incidence ALS and parkinsonism-dementia on Guam. Neurology 1985;35:193-8.

6 Miettinen OS. Theoretical epidemiology. 1st ed. New York: John Wiley 1985:46-83.

7 Breland AE, Currier RD. Multiple sclerosis and amyotrophic lateral scerosis in Mississippi. Neurology 1967;17:1011-6.

8 Campbell AMG, Williams ER, Barltrop D. Motor neuron disease and exposure to lead. J Neurol Neurosurg Psychiatry 1970;33:877-85.

9 Gawel M, Zaiwalla Z, Clifford Rose F. Antecedent events in motor neuron disease. J Neurol Neurosurg Psychiatry 1983;46:1041-3.

10 Murros K, Fogelholm R. Amyotrophic lateral sclerosis in middle-Finland: an epidemiological study. Acta Neurol Scand 1983;67:41-7.

11 Gallagher JP, Sanders M. Trauma and amyotrophic lateral sclerosis: A report of 78 patients. Acta Neurol Scand 1987;75:145-50.

12 Hartog-Jager WA, Hanlo PW, Ansink BJJ, Vermeulen MBM Results of a questionnaire in $100 \mathrm{ALS}$ patients and 100 contro cases. Clin Neurol Neurosurg 1987;89:37-41.

13 Provinciali L, Giovagnoli AR. Antecedent events in amyotrophic lateral sclerosis: do they influence clinical onset and progression? Neuroepidemiology 1990;9:255-62.

14 Chiò A, Meineri P, Tribolo A, Schiffer D. Risk factors in motor neuron disease: a case-control study. Neuroepidemiology 1991;10:174-84.

15 Hanisch R, Dworsky RL, Henderson BE. A search for clues to the cause of amyotrophic lateral sclerosis. Arch Neurol 1976;33:456-7.

16 Pierce-Ruhland R, Patton BM. Repeat study of antecedent events in motor neuron disease. Annals of Clinical Research 1981;13:102-7.

17 Roelofs-Iverson RA, Mulder DW, Elveback LR, Kurland LT, Molgaard CA. Amyotrophic lateral sclerosis and heavy metals: A pilot case-control study Neurology 1984;34:393-5.

${ }_{18}$ Tarras S, Schenkman N, Boesch R, Mulvihill M, Caroscio JT ALS and pet exposure. Neurology 1985;35:717-20.

19 Deapen DM, Henderson BE. A case-control study of amyotrophic lateral sclerosis. Am J Epidemiol 1986;123:790-9.

20 Gresham LS, Molgaard CA, Golbeck AL, Smith R. Amyotrophic lateral sclerosis and occupational heavy metal exposure: a case control study. Neuroepidemiology 1986;5: $29-38$.

21 Sienko DG, Davis JP, Taylor JA, Brooks BR. Amyotrophic lateral sclerosis-a case-control study following detection of a cluster in a small Wisconsin community. Arch Neurol 1990;47:38-41.

22 Felmus MT, Patten BM, Swanke L. Antecedent events in amyotrophic lateral sclerosis. Neurology 1976;26:167-72.

23 Kondo $K$, Tsubaki $T$. Case-control studies of motor neuron disease, association with mechanical injuries. Arch Neurol 1981;38:220-6.

24 Armon C, Kurland LT, Daube JR, O'Brien PC. Epidemiologic correlates of sporadic amyotrophic lateral sclerosis. Neurology 1991;41:1077-84.

25 Kurtzke JF, Beebe GW. Epidemiology of amyotrophic lateral sclerosis: a case-control comparison based on ALS deaths. Neurology 1980;30:453-62. 
26 Gunnarsson L-G, Lindberg G, Söderfeldt B, Axelson O. Amyotrophic lateral sclerosis in Sweden in relation to occupation. Acta Neurol Scand 1991;83:394-8.

27 Dean AD, Dean JA, Burton AH, Dicker RC. Epi Info Version 5. $A$ word processing, database, and statistics program for epidemiology on micro-computers. Mountain, A: USA Incorporated, 1990.

28 Epicenter Software, EPILOG plus. Pasadena, CA: Epicenter Software.

29 Wilkinson, L. SYSTAT: the system for statistics. Evanston, IL; Systat Inc, 1989.
30 Fredrikson M, Hardell L, Bengtsson N-O, Axelson O. Confounding in occupational studies. In: Hogstedt C, Reuterwall C, eds. Progress in occupational epidemiology. Amsterdam: Elsevier Science Publishers, 1988:63-6.

31 Gunnarsson LG, Lindberg G, Söderfeldt B, Axelson O. The mortality of motor neuron disease in Sweden. Arch Neurol 1990;47:42-6.

32 Winokur A, Manaker S, Kreider MS. TRH and TRH receptors in the spinal cord. Ann NY Acad Sci 1989;553:314-24.

Accepted 17 February 1992 